\title{
АНАЛИЗ ФАКТОРОВ, ВЛИЯЮЩИХ НА СОЦИАЛЬНО-ЭКОНОМИЧЕСКОЕ РАЗВИТИЕ ГОСУДАРСТВ В КОНТЕКСТЕ ИННОВАЦИОННЫХ ПРЕОБРАЗОВАНИЙ
}

\section{(C) 2021 Лямин Борис Михайлович}

кандидат экономических наук, старший преподаватель Высшей школы сервиса и торговли Санкт-Петербургский политехнический университет Петра Великого, Россия, Санкт-Петербург E-mail: Lyamin.bm@gmail.com

\section{(c) 2021 Конников Евгений Александрович}

кандидат экономических наук, доцент Высшей инженерно-экономической школы Санкт-Петербургский политехнический университет Петра Великого, Россия, Санкт-Петербург

В ходе проведенного исследования проведен глубокий анализ работ зарубежных авторов в области влияния развития социально-экономических аспектов от количества женщин в политике. Доказана зависимость степени развитости государства от доли женщин в политике, тем самым выявлена необходимость поддерживать инициативы, направленные на вовлечение, в первую очередь, девушек в общественные и политические движения, так как наличие женщин на руководящих постах положительно влияет на социально экономическое положение государства, выраженное следующими показателями: ВВП по паритету покупательской способности, международный индекс счастья и индекс восприятия коррупции

Ключевые слова: инновационные преобразования, уровень развития государства, социальноэкономическое развитие, доля женщин в политике

Современное состояние мировой экономики и кризисные явления показывают, что устойчивое развитие национальных экономик возможно при развитии науки и техники, воплощенных в технологиях, оборудовании и системах квалификации кадров, организации производства. Успешное развитие современной экономики невозможно без повышения конкурентоспособности наукоемкой инновационной продукции в общем объеме ВВП. При этом на социальноэкономическое развитие государства в том числе оказывают влияние и другие факторы, например, количество людей с высшим образованием, внедрение ИКТ в государственные и социальные учреждения, количество внедренных в реальный сектор экономики патентов $[9,10]$. При этом существуют научные школы, утверждающие, что социально - экономическое благополучие жителей в стране зависит в том числе и от количества женщин на руководящих постах на государственных и коммерческих предприятиях. При этом, лидерами в этой области исследований являются зарубежные ученые, поэтому необходимо рассмотреть существующий подход в контексте инновационных преобразований как в России, так и за рубежом.

При формулировке проблемы встает вопрос о том, что является первоочередным явлением: доля женщин в политике влияет на уровень развитости государством, потому что женщины хорошие управленцы или же уровень развитости страны влечет за собой обеспокоенность вопросами гендерного неравенства и в качестве метода борьбы с неравенством предпринимается решение о включении женского населения в число управленцев. Для проверки этих двух гипотез и выбора оптимальной были рассмотрены следующие показатели:

- ВВП по ППС (\$ США),

- ВНД по ППС (\$ США),

- индекс человеческого развития (интегральный показатель, рассчитываемый ежегодно для измерения уровня жизни, грамотности, образованности и долголетия);

- международный индекс счастья (для расчета использованы показатели субъективной удовлетворенности людей жизнью, ожидаемой продолжительности жизни и «экологического следа»);

- индекс восприятия коррупции (основывается на независимых опросах, в которых принимают участие международные финансовые и правозащитные эксперты);

- уровень здравоохранения (\% от ВВП);

- доля женщин в политике. 
Как уже было отмечено ранее, существует множество зарубежных работ, исследующих данные зависимости, для разработки концептуальной модели исследования проведем их анализ.

Учеными из Великобритании Sonia Bhalotra и Irma Clots Figueras было обнаружено, что увеличение на одно стандартное отклонение в политической репрезентации женщин приводит к сокращению неонатальных смертей (смертей в первый месяц жизни) на 1,5\% [1]. Также авторы сделали вывод, что женщины с большей вероятностью будут строить государственные учреждения здравоохранения и поощрять дородовой уход и иммунизацию. Их теорию подтверждает ученый Astghik Mavisakalyan [5].

Вопросы влияния женщин в политике на решение климатических проблем поднимают в своем исследовании A Mavisakalyan, Y Tarverdi. Они считают, что представленность женщин в политике поможет решить проблему изменения климата, потому что женщины-политики принимают более жесткие меры в отношении изменения климата, что в свою очередь приводит к снижению выбросов углекислого газа [6].

Также представленность женского пола в политике позитивно влияет на сферу образования. Это доказала Irma Clots-Figueras, получив вывод, что с увеличением политической представленности женщин увеличивается вероятность того, что человек получит начальное образование [2].

Авторы D. S. Jayasuriya, P.J.Burke исследуют влияние политического представительства женщин на экономический рост [4]. Результаты показали, что в последние десятилетия в странах с более высокой долей женщин в парламенте экономика росла быстрее. В свою очередь I Gulakov и F Vanclay провели оценку проблем гендерного равенства в России [3], чтобы измерить уровень прогресса во всех областях общественной и политической жизни страны и выявили, что в стране до сих пор сохраняются гендерные разрывы, как например разрыв в оплате труда, что не свойственно более экономически развитым странам.

Таким образом, исходя из проведенного анализа зарубежной научной литературы можно сделать вывод, что увеличение представленности женщин в политической сфере государства влечет за собой положительные изменения различных показателей степени развитости этого государства. При этом, состоятельной может быть и гипотеза об обратной зависимости. Чем выше уровень жизни в стране, тем более ее граждане обеспокоены социальными проблемами, в частности проблемой гендерного неравенства, из чего следует наибольшая репрезентация женщин в политике как механизм борьбы с дискриминацией по гендерному признаку.

Для оценки выявленных гипотез был использован метод корреляционно-регрессионного анализа. Выборка представлена 52 странами, в которую входят как развитые, так и развивающиеся страны. Переменные соответствуют приведенным выше показателям: ВВП по ППС, ВНД по ППС, индекс человеческого развития, международный индекс счастья, индекс восприятия коррупции и уровень здравоохранения. Данные по доле женщин в парламенте были собраны из источника Inter-Parliamentary Union Open Data [11] и представляют собой долю числа женщин из общего числа представителей нижних палат парламента. Сбор данных для проведения исследования осуществлен при использовании статистических данных Всемирного Банка (World Bank), Организации экономического сотрудничества и развития (OECD), базы данных $\mathrm{OOH}$ (the United Nations) и ВО3 [7, 8].

Для проведения исследования была сформулирована концептуальная модель взаимовлияния факторов (рис. 1).

Показатель доли женщин в политике в данной модели является центральным, но поскольку цель исследования - определить, что является первоочередным - уровень развитости страны или доля женщин в парламенте, мы строим две гипотезы влияния, которые будем изучать независимо друг от друга. Первая - доля женщин в политике влияет на степень развитости государства, в ходе которой мы будем исследовать влияние доли женщин на каждый фактор, оценивающий уровень развития государства, методом парной регрессии. Вторая - уровень развитости государства влияет на степень представленности женщин в парламенте. Эту зависимость будем оценивать методом множественной регрессии. 


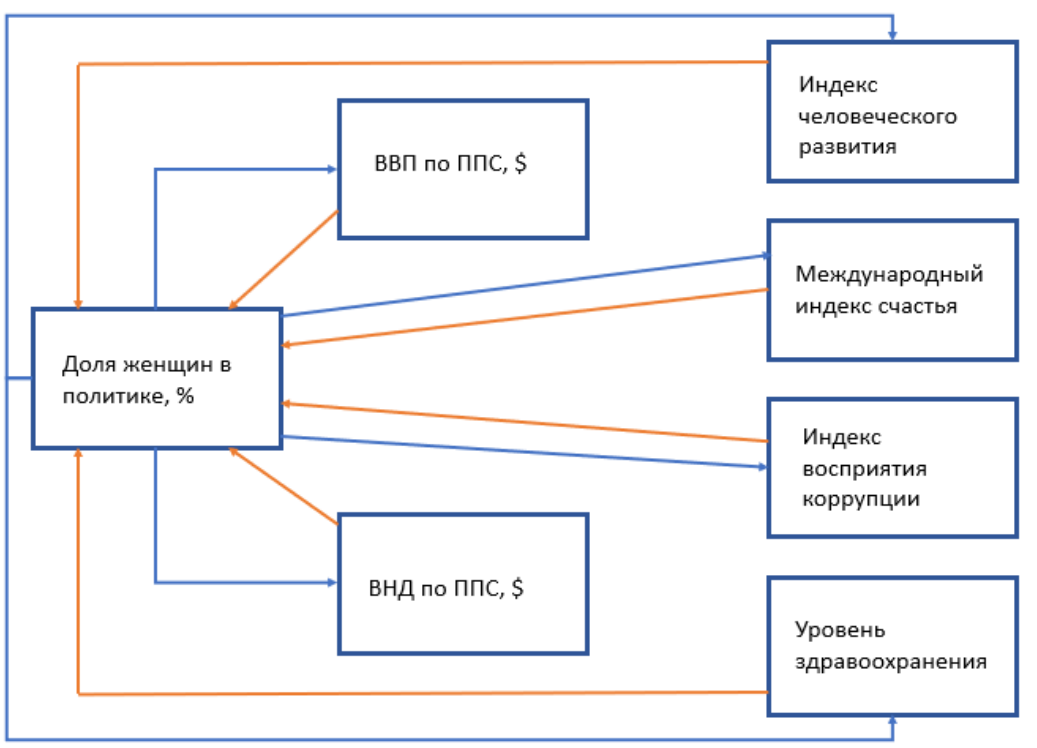

Puc. 1. Концептуальная модель

Связи между показателями, отраженные в концептуальной модели, представлены в виде потенциальных уравнений регрессии.

$$
\begin{aligned}
& \mathrm{Z} 2=\mathrm{a}+\mathrm{b} 1 * \mathrm{Z} 1 \\
& \mathrm{Z} 3=\mathrm{a}+\mathrm{b} 2 * \mathrm{Z} 1 \\
& \mathrm{Z} 4=\mathrm{a}+\mathrm{b} 3 * \mathrm{Z} 1 \\
& \mathrm{Z} 5=\mathrm{a}+\mathrm{b} 4 * \mathrm{Z} 1 \\
& \mathrm{Z} 6=\mathrm{a}+\mathrm{b} 5 * \mathrm{Z} 1 \\
& \mathrm{Z} 7=\mathrm{a}+\mathrm{b} 6 * \mathrm{Z} 1 \\
& \mathrm{Z} 1=\mathrm{a}+\mathrm{b} 7 * \mathrm{Z} 2+\mathrm{b} 8 * \mathrm{Z} 3+\mathrm{b} 9 * \mathrm{Z} 4+\mathrm{b} 10 * \mathrm{Z} 5+ \\
& \mathrm{b} 11 * \mathrm{Z} 6+\mathrm{b} 12 * \mathrm{Z} 7
\end{aligned}
$$

В качестве критериев, на основании которых будет проводиться оценка качества моделей выступают: p-level, коэффициент детерминации $\mathrm{R}^{2}$, F-критерий Фишера, ошибка аппроксимации (A), относительный коэффициент эластичности (Э).

В результате проведенного анализа двух гипотез было выявлено, что первая гипотеза - доля женщин в политике является независимой переменной, оказывающей положительное влияние на степень развитости государства. Вторая гипотеза - доля женщин в политике - это зависимая переменная, рост которой обусловлен общей развитостью страны. На основании проведенного анализа можно сделать следующие выводы.

Во-первых, не каждый показатель, выбранный для оценки уровня развитости государства, состоит в сильной зависимости от доли женщин в политике. Наиболее полно она влияет на международный индекс счастья, ВВП по ППС и на индекс восприятия коррупции.

Во-вторых, гипотеза номер 2 показала результаты в целом хуже, чем гипотеза номер 1.
Несмотря на то, что модель является достоверной, осталась только одна переменная, оказывающая положительное влияние на долю женщин в политике и одна, показывающая обратную зависимость, что противоречит базовым понятиям о гендерном равенстве. Данную модель можно попытаться оптимизировать, добавив больше независимых переменных, с тем расчетом, что сами эти независимые переменные не будут оказывать влияние друг на друга.

Таким образом, на основе проведенного анализа было выявлено, что статистически более значимо влияние доли женщин в политике на уровень развитости государства, поэтому принимаем первую гипотезу и строим новую концептуальную модель (рис. 2).

В ходе проведенного исследования была доказана зависимость степени развитости государства от доли женщин в политике, тем самым выявлена необходимость поддерживать инициативы, направленные на вовлечение, в первую очередь, девушек в общественные и политические движения, так как наличие женщин на руководящих постах положительно влияет на социально экономическое положение государства, выраженное следующими показателями: ВВП по паритету покупательской способности, международный индекс счастья и индекс восприятия коррупции. Вместе с тем, необходимы дальнейшие более глубокие исследования с применением автоматизированных алгоритмов, которые бы более точно выявили влияние доли женщин в политике на экономическое развитие государства в условиях инновационных преобразований. 


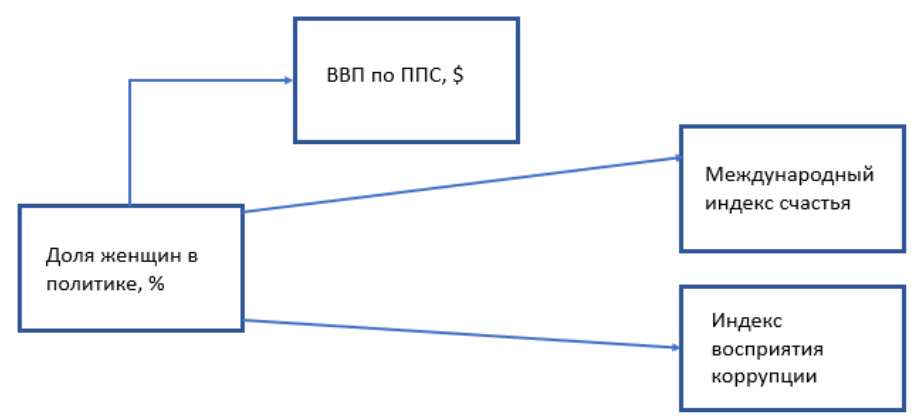

Puc. 2. Подтвержденная концептуальная модель

\section{Библиографический список}

1. Bhalotra S., Clots-Figueras I. Health and the political agency of women // American Economic Journal: Economic Policy. 2014. № 2 (6). C. 164-197.

2. Clots-Figueras I. Are female leaders good for education?: Evidence from India 2007.

3. Gulakov I., Vanclay F. Social impact assessment in the Russian Federation: does it meet the key values of democracy and civil society? // Impact Assessment and Project Appraisal. 2018. № 6 (36). C. 494-505.

4. Jayasuriya D. S., Burke P.J. Female parliamentarians and economic growth: Evidence from a large panel // Applied Economics Letters. 2013. № 3 (20). C. 304-307.

5. Mavisakalyan A. Women in cabinet and public health spending: evidence across countries // Economics of Governance. 2014. № 3 (15). C. 281-304.

6. Mavisakalyan A., Tarverdi Y. Gender and climate change: Do female parliamentarians make difference? // European Journal of Political Economy. 2019. (56). C. 151-164.

7. Забелин Б. Ф., Конников Е. А. Менеджмент: планирование, организация 2019.

8. Конникова О. А., Конников Е.А. Синтаксический анализ поведения потребителей в цифровой среде $2020 . С$. 132-145.

9. Лямин, Б М, Конников, Е.А., Бурова А. Ю. Стимулирование инновационной деятельности в вузе в условиях цифровой экономики // Аудит и финансовый анализ. 2020. (2). С. С. 192-196.

10. Лямин Б.М. Анализ ключевых факторов, влияющих на инновационные преобразования на предприятиях торговой отрасли // Исследование, систематизация, кооперация, развитие, анализ социальноэкономических систем в области экономики и управления (ИСКРА - 2018). Сборник трудов I Всероссийской школы молодых ученых. 2018. С. С. 185-190.

11. Inter-parliamentary Union (2020). Women in parliament: 1995-2020-25 years in review. Available from https:// www.ipu.org/resources/publications/reports/2020-03/women-in-parliament-1995-2020-25-years-in-review. 